\title{
A construção da identidade profissional na adultez em emergência: narrativas de uma jovem sobre o ser estudante e trabalhadora ${ }^{1}$
}

\section{Professional identity construction in emerging adulthood: an young woman 's narratives about being a student and worker}

\author{
Ana Paula Carlucci* \\ Universidade de Brasília - UnB, Brasília, DF, Brasil
}

Silviane Bonaccorsi Barbato**

Universidade de Brasília - UnB, Brasília, DF, Brasil

Olgamir Francisco de Carvalho***

Universidade de Brasília - UnB, Brasília, DF, Brasil

\begin{abstract}
RESUMO
Os jovens dos países industrializados participam de contextos socioculturais em constante transformação e incertezas que demandam a construção de novas ações e significados referentes aos posicionamentos-eu. Para compreendermos as mudanças na adultez em emergência, analisamos um estudo de caso que compõe um projeto integrado de pesquisa, que objetivou entender a construção de significados e de posicionamentos sobre ser jovem, estudante e trabalhador no Distrito Federal. A estudante participou de cinco sessões de entrevistas: a) entrevista individual semiestruturada; b) episódica seguida por entrevista com mediação de objetos; c) mediada por atividade escrita de complementação de frases; d) mediada por construção de linha do tempo; e) mediada por imagens. Aplicou-se a análise dialógica temática. Os resultados indicaram que a identidade profissional da participante foi construída na tensão entre os diferentes posicionamentos e significados na relação escola-trabalho, nos quais os marcadores temporais presentes relacionados ao evento de impacto nas narrativas direcionaram o seu vetor de desenvolvimento para novas formas de pensar, sentir e agir próprias da adultez.
\end{abstract}

Palavras-chave: Adultez em emergência, Identidade profissional, Significados, Posicionamentos.

\begin{abstract}
Young people in industrialized countries take part in sociocultural contexts facing constant transformation and uncertainty that require the construction of new actions and meanings composing I-positions. In order to understand transformation in emerging adulthood, we analyzed a case study which is part of a main research aimed at studying the construction of positions about being a young student and worker in the Brazilian capital geopolitical area. A young woman took part in five interview sessions - a) a semistructured interview; b) an episodic interview followed by another mediated
\end{abstract}


by objects; c) an interview mediated by a writing activity of completing phrases; d) a fourth session mediated by the construction of lines of time; and e) a last session mediated by images. A thematic dialogical analyzes was applied. Results indicated that her professional identity was built in the tension between different positions and meanings in the relation between school and work in which time markers related to an event of impact present in the narratives directed her development vector towards new ways of thinking, feeling and acting characteristic of adulthood.

Keywords: Emerging adulthood, Professional identity, Meanings, Ipositions.

\section{I ntrodução}

Neste artigo, dentre as mudanças vivenciadas pelos jovens em transição para a vida adulta, destacamos a transição da escola para a atividade laboral como um processo complexo em que a inserção profissional dos jovens é o elemento fundamental para a sua integração enquanto adultos, na sociedade brasileira atual. O jovem produz significados concretizados em enunciados durante a interlocução (BAKHTIN, 1992; VOLOCHINOV, 2002) que se efetua num dado contexto situacional num dado cronotopo, ou seja, na relação de interdependência entre espaço e tempo. Ao concretizarem as relações dialógicas de reflexo e refração entre o eu e o outro num tempo e espaço específicos, as interações possibilitam a análise de textos produzidos com enfoque na tensão entre as forças centrípetas (de permanência de significados) e centrífugas (de mudança) em jogo no sistema cultural em que o jovem se insere (BAKHTIN, 1981; BAKHTIN, 1993).

No presente trabalho, o discurso construído pelos jovens em suas relações intersubjetivas é concebido como uma ponte lançada entre os interlocutores em contextos situados, onde as vozes dos outros entram em tensão com a voz pessoal. O sentido na narrativa nasce do encontro concreto do eu com o outro, onde o interlocutor-ouvinte que compreende a significação lingüística de um discurso adota, para com este discurso, uma atitude responsiva ativa: ele concorda, discorda, completa, adapta, e esta atitude responsiva ativa está em constante elaboração durante a relação dialógica (BAKHTIN, 1992).

Do ponto de vista do dialogismo, a pessoa ao participar de diferentes interlocuções se depara, constrói e atualiza significados relacionados a valores, crenças, idéias e práticas que foram produzidas no decorrer da história coletiva e pessoal. É neste jogo polifônico que a pessoa constrói sua voz singular (BAKHTIN, 1992; VOLOCHINOV, 2002).

O contexto sociocultural pode, então, ser definido como um conjunto de signos que media a construção de significados do modo de agir e sentir e que regula a construção de outros significados também compartilhados culturalmente (VALSINER, 2007). Nas relações socioculturais, são produzidas as ferramentas e signos mediadores 
que oferecem suporte (BRUNER, 1975) aos interlocutores, na busca de suas próprias satisfações e nas transformações de si, do outro e dos contextos em que vivem (VALSINER, 2007; VALSINER; CONNOLLY, 2003; VALSINER; ROSA, 2007).

Nesse sentido, os jovens se constituem no jogo com o coletivo e produzem os significados sobre o que eles poderiam se tornar, o que eles gostariam de se tornar e temem se tornar, constituindo-se a partir de uma pluralidade de possíveis selves, ou como denomina Bruner (1997) "si-mesmos", em tensão com o si-mesmo (BRUNER, 1997; BRUNER; FELDMAN, 1996) que se concretiza nas esferas comuns (BAKHTIN, 1993; SANTOS; BARBATO, 2006).

O Eu, como autor, cria o futuro e reconstrói o passado a partir das relações existentes e estabelecidas entre as várias vozes conforme as diferentes posições que ocupa ao longo da vida. Sendo assim, o simesmo é compreendido como uma multiplicidade dinâmica de posicionamentos inter-relacionados em um cronotopo, onde os posicionamentos podem mudar e até ocupar posições opostas conforme as mudanças espaço-temporais (HERMANS; KEMPEN; VAN LOON, 1992).

Considerando esses princípios, o presente trabalho objetivou analisar os significados que compõem os posicionamentos de estudante e trabalhadora de uma jovem do Distrito Federal.

O período entre o final da adolescência e o início da fase adulta, denominado como adultez em emergência, como qualquer outro período do desenvolvimento é construído cultural e historicamente e tem se tornado um período distinto no curso de vida para os jovens dos países industrializados (BERK, 2006; JENSEN, 2000). Os jovens entre o final da adolescência e o início da vida adulta vivem um momento de transição marcado por mudanças em vários níveis: social, psicológico e cultural que, por sua vez, geram a necessidade de novas formas de agir, pensar e sentir. A transição, nesse sentido, perfaz momentos marcados por tensões acirradas, conflituosas e críticas entre os modelos pessoais preexistentes e as novas informações presentes nos contextos interpessoais (CARLUCCI, 2008).

Entendemos a narrativa como um instrumento que media o mundo canônico da cultura e o mundo idiossincrásico dos desejos, crenças e valores das pessoas (BRUNER, 1997). A narrativa é utilizada neste trabalho como um instrumento cultural que organiza os eventos vividos (BRUNER, 1997; DAVIES; HARRÉ, 1999; GERGEN, 2001; VIGOTSKI, 1998; 2001) e os posicionamentos são entendidos como um processo de discurso no qual o self (si-mesmo) é concretizado na relação dialógica (BAKHTIN, 1981). Essas mudanças possibilitam a emergência de diferentes valorações sobre as experiências vividas, à medida que cada vivência possui um valor, um peso, um significado diferente para a pessoa. O si-mesmo é construído, portanto, na 
relação dialética entre os aspectos coletivos e pessoais no momento da interlocução (HERMANS, 2001; HERMANS; KEMPEN; VAN LOON, 1992; JOSEPHS, 2002).

Os processos narrativos podem indicar as ações e significados construídos pelo jovem ao explicar-se, posicionando-se em relação ao mundo a partir do presente, interpretando o passado e planejando o futuro. Ressaltamos, ainda, que nesses processos, a valoração é qualquer unidade de significado que tem um valor positivo, negativo ou ambíguo (HERMANS; HERMANS-JANSEN, 2003). Assim, os significados são produzidos pelo impacto da ideologia, isto é, dos significados sociais expressos em discursos hegemônicos (GRAMSCl, 1966) pelos interesses concretos, definidos historicamente na contradição de classe (CHAUÍ, 2006) e pela emoção (SANTOS; BARBATO, 2006). Nessa tensão uma fronteira emerge entre os significados antigos e os novos, direcionando o jovem para a negociação, na relação dialética entre aceitação e resistência. Ao participar das interações socioculturais ele/ela constrói sua agencialidade, definida neste texto como sua capacidade e habilidade para atuar reflexivamente sobre o mundo (BRUNER, 1986).

Autores enfatizam (BRUNER, 1986; BROCKMEIER, 2009) ainda que a agencialidade está sob o domínio de estados intencionais como crenças, desejos e emoções. Portanto, faz-se necessário considerar os significados produzidos nas narrativas como formas de agencialidade. Sendo assim, o jovem na sua relação com o meio, utiliza a comunicação como uma atividade social que, por um lado, coloca em questão os seus posicionamentos-eu e, por outro, direciona-o a integrar-se nos diferentes espaços de intersubjetividade (ROMMETVEIT, 1979).

Dessa forma, as diversas interlocuções estruturam as fronteiras espaciais, sociais e culturais na produção de significados e posicionamentos, possibilitando condições para que o jovem se torne autor (VOLOCHINOV, 2002), agente, além de ator, nos vários cenários em que ele participa e constrói (VALSINER; ROSA, 2007).

Ao enfocarmos a adultez em emergência, podemos refletir que no processo de integração ou de socialização laboral, as expectativas, valores e crenças de um indivíduo interagem com as da organização, iniciando-se um processo de integração e negociação, através do qual o indivíduo procura tornar essas exigências compatíveis com as suas expectativas e necessidades. Esse processo é influenciado, por exemplo, por fatores como a sua motivação ao ingressar na vida ativa e sua interpretação sobre as relações e papéis exercidos pelos sistemas de ensino e produtivo.

Um aspecto a ser destacado nesse processo é que a transição tem se tornado cada vez mais complexa e prolongada, em virtude de diferentes fatores, dentre eles, a pouca adequação entre a formação e as necessidades do trabalho e a relação entre o processo de 
desenvolvimento pessoal e a escolha profissional dos jovens, num contexto de globalização (CARVALHO, 2005). A globalização transformou a organização e a divisão do trabalho que, atualmente, demanda uma maior flexibilidade técnica, humana, organizacional e cultural. Do ponto de vista da organização, os novos métodos de produção "usam pouco trabalho, geram desemprego, subemprego, jornadas de tempo parcial, trabalho temporário e outras formas atípicas" (PASTORE, 1995, p. 31). Deste ponto de vista "não basta mais que o trabalhador saiba fazer; é preciso também conhecer e, acima de tudo, saber aprender" (LEITE, 1995, p. 14). Do ponto de vista da cultura, "o novo modelo de produção flexível envolve também padrões e valores políticos, religiosos e socioculturais" (LEITE, 1995, p. 11).

Nesse contexto de mudanças e transformações da organização e da divisão de trabalho, um novo cenário emerge para o mercado e para o trabalhador demandando um perfil diferenciado e um novo conceito de qualificação que enfatize a competência profissional. Segundo Leite (1995), as empresas esperam do trabalhador competência e que compartilhe as mesmas visões de mundo, para que possa pensar com ela.

Vários autores (FRIGOTTO, 1998; LEITE, 1995; MANFREDI, 2003; PASTORE, 1995; RACHID; GITAHY, 1995) apontam que no processo complexo e dialético entre o trabalho e a escola criou-se a necessidade de se universalizar a escola como um lugar preparatório para a inserção no mercado de trabalho. Ao mesmo tempo em que se passou a exigir dos empregados uma formação técnico-científica mais abrangente e multifacetada. Nesse cenário, as incertezas surgem na medida em que é exigido do trabalhador que ele seja polivalente e participativo e que tenha iniciativa, raciocínio lógico e discernimento bem desenvolvidos. Por outro lado, espera-se que a educação e a formação continuadas possibilitem o desenvolvimento da compreensão e crítica reflexiva próprias de um fazer autônomo e eticamente referenciado de participação cidadã.

Ao enfocarmos a escola, vamos tratar particularmente da Educação de Jovens e Adultos (EJA). A EJA caracteriza-se como uma modalidade da educação básica que tem como alvo o jovem e o adulto pertencentes às diferentes classes socioeconômicas, que trabalham ou procuram emprego e que, por diferentes motivos, não terminaram ou não tiveram acesso ao ensino médio e fundamental (DORNAS, 1997). O retorno do aluno à escola visa diminuir a distorção idade/ano de escolarização e possibilitar novas inserções, incluindo-se o estágio em empresas associadas aos sistemas de ensino, na vida social, cultural e política da sociedade.

Tendo essas características em vista, a proposta político-pedagógica da EJA busca considerar em suas ações práticas e pedagógicas as situações, experiências de vida dos jovens e adultos e as 
características dessa clientela, considerando os direitos e oportunidades no que tange à educação, visando a diminuição da desigualdade (BRASIL, 2001).

\section{O processo de investigação}

Utilizamos a metodologia qualitativa para a análise de um estudo de caso, à medida que concebemos a pesquisa empírica como um processo cíclico e dinâmico (BRANCO; ROCHA, 1998; WINEGAR, 1997). Na construção da interpretação, as informações empíricas relacionam-se dialeticamente com a perspectiva teórica, mediando e gerando a construção de novos significados (CRESWELL, 1998, MEY, 2000). A análise de estudos de caso, por sua vez, possibilita o enfoque na identificação dos significados que formam os posicionamentos.

Optamos pela apresentação de um estudo de caso de um projeto integrada de pesquisa ( $N$ o de Registro no SISNEP e no Comitê de Ética: FR - 165211; 129/2007) sobre identidade profissional (CARLUCCI, 2008; SANTOS; BARBATO, 2006) entendendo que a narrativa, enquanto instrumento metodológico, consiste em uma ferramenta interativa que adquire sentido no jogo polifônico das enunciações concretizadas na interação.

Os dados foram coletados em uma escola de Ensino Médio da Secretaria de Educação do Distrito Federal, sendo o único prérequisito ser uma instituição de ensino voltada para estudantes trabalhadores e estagiários. Na escola, o SOE (Setor de Orientação ao Estudante) é o setor responsável para lidar com a parceria escolaempresa da Secretaria de Educação do Distrito Federal, cuja coordenação cadastra os jovens estudantes, fiscaliza suas atividades laborais e a dos parceiros e tira suas dúvidas.

A escolha da participante foi realizada a partir de uma lista composta pelos alunos que trabalhavam, fornecida pela escola. Por meio desta lista, a pesquisadora entrou em contato com a aluna e a convidou para a pesquisa.

Maria, nome fictício, é uma jovem brasiliense, de 21 anos, estudante do 3 o ano do Ensino Médio na EJA noturno, de uma escola pública, estagiária de um banco do Distrito Federal, separada, mãe de uma filha de seis anos. No momento da entrevista morava com a mãe, os irmãos e sua filha em uma Região Administrativa do Distrito Federal.

Para a construção das informações empíricas, foram realizadas individualmente cinco entrevistas agendadas previamente com a participante, sendo realizadas no próprio colégio e em horários diferentes dos das aulas. Cada entrevista durou aproximadamente 50 minutos. O conjunto de entrevistas totalizou aproximadamente 4 horas e 30 minutos de gravação em audio, com utilização de gravador digital. Em cada sessão era explicado o procedimento de sua realização e a participante era encorajada a falar. 
Primeiramente foi realizada a entrevista individual semi-estruturada com um roteiro previamente elaborado em que se privilegiou num primeiro momento a narrativa livre sobre o trabalho e a escola na vida da participante. Ao final da sessão foi pedido à participante que levasse para a entrevista seguinte um objeto que representasse a relação entre escola e trabalho.

Na segunda sessão, optou-se por uma entrevista episódica (BAUER; GASKELL, 2004) em que a pesquisadora retomou alguns eventos narrados na primeira sessão e pediu à participante que contasse como ocorreu a escolha do objeto e argumentasse sobre os seus significados para ela. $\mathrm{Na}$ terceira sessão, foi, então, pedido à participante que completasse frases a partir de um roteiro previamente elaborado que enfocava temas referentes ao ser jovem, ser estudante, trabalhadora e as relações dessas posições com sua história de vida: meu passado, meu presente, no futuro eu quero. Esta atividade mediou o segundo momento da entrevista.

$\mathrm{Na}$ quarta sessão, Linha do Tempo (CORREIA, 2001), foram fornecidas explicações sobre como a atividade iria ser desenvolvida para que a participante tecesse uma ou mais linhas temporais, se necessário, que representassem sua história na escola e sua história no trabalho. Ao final daquela sessão, a pesquisadora, considerando os desenhos da linha do tempo e as narrativas e argumentações da participante, buscou esclarecer os significados produzidos e, por último, repassou uma máquina fotográfica do tipo semi-automática com filme de 12 poses para que a participante tirasse fotos que representassem a relação escola-trabalho.

$\mathrm{Na}$ última sessão, a entrevista foi mediada pelas imagens produzidas (CAIXETA, 2001). A pesquisadora pediu para a participante contar como foi o processo e sobre o significado de cada foto para ela.

Utilizou-se a análise temática dialógica em que as entrevistas são transcritas, lidas e relidas várias vezes para a identificação de temas que regulavam sua narrativa, dos posicionamentos e os seus significados, por meio da construção de um referencial de codificação em que o texto foi gradualmente reduzido, tendo as enunciações como unidade de análise (LINELL, 1995; VOLOSINOV, 2002; BARBATO; CAIXETO; MELO, 2003). Os aspectos polifônicos foram construídos a partir da diferenciação dos sentidos que constituíram os temas (LINELL, 1995). A partir desse procedimento, foram construídos mapas que são representações gráficas de relações e movimentos entre os significados (BARBATO, CAIXETA, aceito).

Nos mapas, cada seta representa a relação circular e interdependente entre os diferentes elementos marcadores do ser jovem, estudante e trabalhadora nas narrativas de Maria. Nessa circularidade e interdependência, marcamos o jogo temporal e as características dos posicionamentos e dos significados construídos nas entrevistas a partir da valoração construída pela participante (emoções, 
qualidades, resultados, ações e metas) (BRUNER, 1997; HERMANS; HERMANS-J ANSEN, 2003).

\section{Resultados}

Maria narra sua história de vida como sendo marcada por momentos de muitas dificuldades, alternando entre momentos bons e ruins. As narrativas são organizadas a partir de marcas temporais como: (a) antes, mediado por significados de sua vivência no colégio desde a educação infantil até o ensino fundamental; (b) depois, marcado por significados mediados pela experiência da gravidez e nascimento de sua filha no final do ensino fundamental; e (c) agora, mediados pelos significados de sua vivência no ensino médio e sua entrada no estágio e no mundo do trabalho.

O primeiro momento é representado pelo handebol, que a impulsionava a continuar estudando para, no futuro, se tornar uma profissional. O segundo momento é representado pela gravidez na adolescência, evento de impacto que desencadeou sua saída da equipe do colégio, do handebol e o abandono dos planos de se tornar uma atleta profissional. Naquele momento, para ela, estudar perdera a importância em relação à responsabilidade de ser mãe. Mesmo assim, ainda ia à escola para se encontrar "com os colegas, beber, fumar", evidenciando a tensão dessa passagem na mudança no direcionamento do vetor do desenvolvimento, visto que essas ações são classificadas como coisa de "criançola". No terceiro momento, narrou sobre a entrada no mercado de trabalho trabalhando como auxiliar de cozinha, como vendedora em uma exposição agropecuária e em uma padaria. O impacto das experiências de gravidez e maternidade, da aprendizagem nos diferentes empregos e do salário que proporcionou independência e autonomia, possivelmente, desencadearam os processos de reflexão e mudança nos significados de escola em sua narrativa: a escola de um lugar de diversão passa a ser um espaço que a prepara para a vida e para o mercado de trabalho.

Ao enfocar a relação escola-trabalho a pedido da pesquisadora, Maria, ao longo das cinco sessões, constrói as mudanças de significados dessa relação, permeando-as pelo impacto da gravidezmaternidade na adolescência. Os significados foram marcados pela recorrência de três temas centrais que se inter-relacionam e regulam os diferentes posicionamentos: emprego bom, independência e vida dura, conforme mostra o quadro 01. 
Quadro 01: temas centrais de Maria na relação trabalho-escola

\begin{tabular}{|l|l|}
\hline Temas & Significados \\
\hline \multirow{4}{*}{ Emprego bom } & Educação \\
\cline { 2 - 2 } & Independência \\
\cline { 2 - 2 } & Crescimento pessoal, profissional e financeiro \\
\hline \multirow{4}{*}{ Independência } & Dinheiro \\
\cline { 2 - 2 } & Autonomia \\
\cline { 2 - 2 } & Liberdade \\
\cline { 2 - 2 } Vida Dura & Respeito \\
\cline { 2 - 2 } (valor positivo) & Inclusão \\
\hline \multirow{3}{*}{$\begin{array}{l}\text { Vida Dura } \\
\text { (valor negativo) }\end{array}$} & Realização \\
\cline { 2 - 2 } & Felicidade \\
\cline { 2 - 2 } & Equilíbrio \\
\cline { 2 - 2 } & Crescimento pessoal, profissional e financeiro \\
\hline & Sofrimento \\
\cline { 2 - 2 } & Cansaço \\
\cline { 2 - 2 } & Estresse \\
\hline
\end{tabular}

À medida que Maria se posicionava em relação à escola e ao trabalho, construía os temas e seus significados.

Os posicionamentos foram construídos na tensão entre passado, presente e futuro, sendo compostos pelos significados descritos no quadro 02:

Quadro 02: posicionamentos de Maria na relação trabalho-escola

\begin{tabular}{|c|c|c|c|}
\hline Posicionamentos & Passado & Presente & Futuro \\
\hline \multirow{4}{*}{ Ser jovem } & $\begin{array}{l}\text { Momento } \\
\text { tumultuado }\end{array}$ & $\begin{array}{l}\text { Início da vida } \\
\text { adulta }\end{array}$ & Maturidade \\
\hline & $\begin{array}{l}\text { Momento } \\
\text { estranho }\end{array}$ & $\begin{array}{l}\text { Definição de } \\
\text { futuro }\end{array}$ & Independência \\
\hline & $\begin{array}{l}\text { Descoberta } \mathrm{da} \\
\text { maturidade }\end{array}$ & & Responsabilidade \\
\hline & $\begin{array}{l}\text { Descoberta do } \\
\text { caráter }\end{array}$ & & \\
\hline \multirow{2}{*}{ Ser estudante } & $\begin{array}{ll}\text { Entrada } & \text { na } \\
\text { escola } & \end{array}$ & $\begin{array}{l}\text { Entrada no } \\
\text { ensino médio }\end{array}$ & Se formar na faculdade \\
\hline & $\begin{array}{ll}\text { Entrada } & \text { no } \\
\text { ensino } & \\
\text { fundamental } & \\
\end{array}$ & $\begin{array}{ll}\text { Jogada } & \text { no } \\
\text { mundão } & \end{array}$ & \\
\hline \multirow{4}{*}{ Ser trabalhadora } & $\begin{array}{l}\text { Trabalho } \\
\text { informal }\end{array}$ & Estágio & $\begin{array}{l}\text { Entrada no mundo do } \\
\text { trabalho }\end{array}$ \\
\hline & Sem educação & & $\begin{array}{l}\text { Entrada no mundo } \\
\text { adulto }\end{array}$ \\
\hline & Sofredora & & \\
\hline & Responsabilidade & & \\
\hline
\end{tabular}


Ana Paula Carlucci, Silviane Bonaccorsi Barbato, Olgamir Francisco de Carvalho A construção da identidade profissional na adultez em emergência

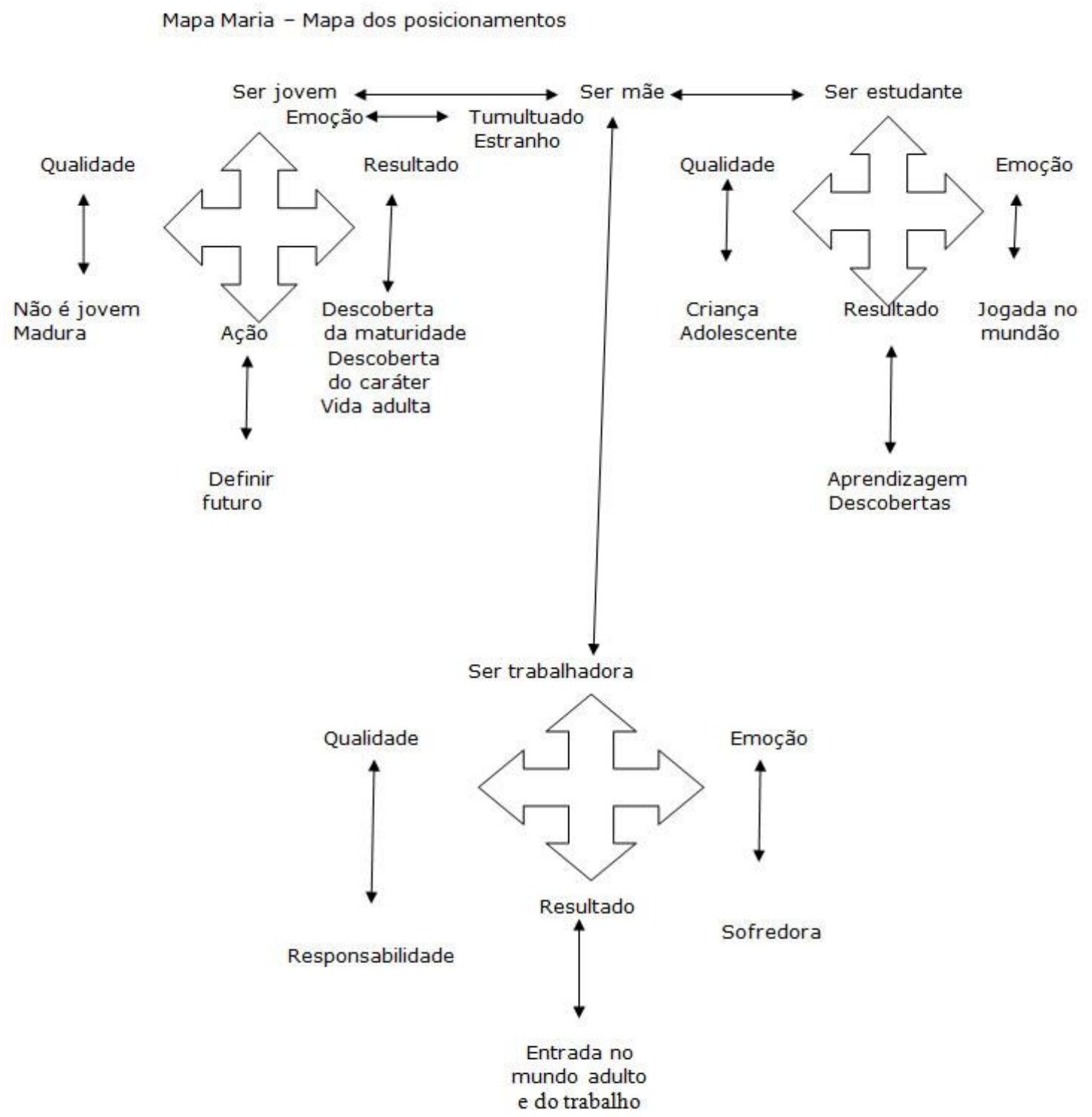

Estud. pesqui. psicol., Rio de Janeiro, v. 11, n. 2, p. 566-589, 2011. 
Ana Paula Carlucci, Silviane Bonaccorsi Barbato, Olgamir Francisco de Carvalho A construção da identidade profissional na adultez em emergência

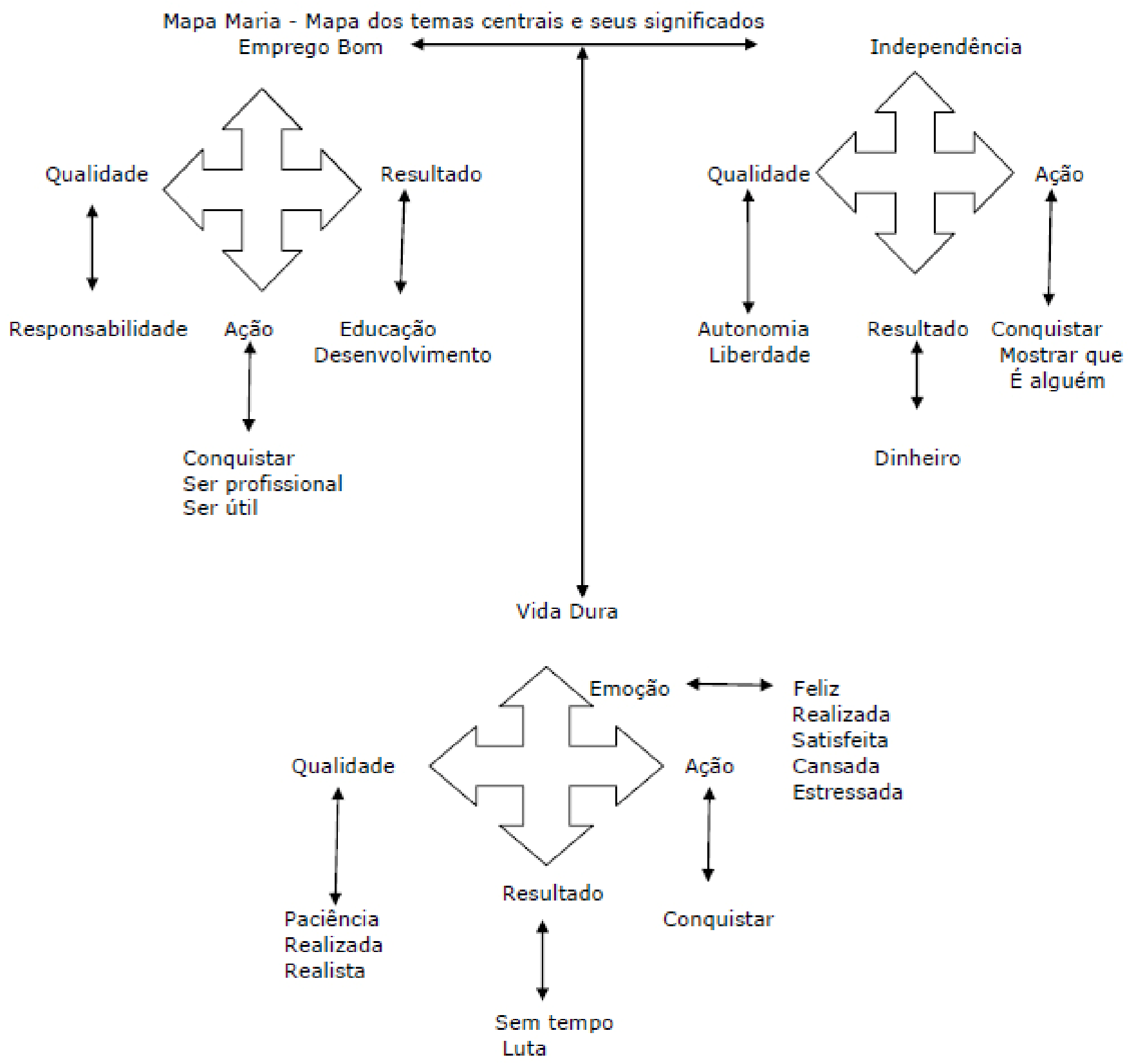

Estud. pesqui. psicol., Rio de Janeiro, v. 11, n. 2, p. 566-589, 2011. 


\section{Discussão}

Os resultados corroboraram com os indicadores da literatura sobre a transição, marcada por momentos de mudança (LAWRENCE; DODDS, 2007; SHANAHAN, 2000) que, por sua vez, são geradas e geram tensões acirradas, conflituosas e críticas entre os modelos pessoais preexistentes e as novas informações presentes nos contextos interpessoais (BALL, 2005; CARLUCCI, 2008; SANTOS; BARBATO, 2006). Na transição, no caso de Maria, o impacto da gravidez e maternidade aos 15 anos pode ser interpretado como uma fronteira que emergiu entre os significados antigos e os novos (ABBEY; VALSINER, 2005), em processos de negociação e resistência, direcionando-a para a vida adulta.

A fronteira emerge entre os significados antigos, em que ela não se sentia "estressada", "preocupada", "sem tempo", "cansada" e na "luta", produzindo uma tensão entre as crenças, as visões de mundo, os objetivos e os valores antigos e os novos. E, nessa tensão, Maria não se contenta apenas em manifestar sua discordância e seu protesto, ela "resiste a todas com todas as forças de suas tradições, procurando e tentando seu equilíbrio antigo sob novas condições" (HALLBWACHS, 2006, p. 137). Nesse sentido, o desenvolvimento é um processo no qual a pessoa, ao mesmo tempo se sujeita, se adapta e resiste, se opõe, aceita, questiona, interage e transforma a cultura em algo novo e pessoal (VALSINER; ROSA, 2007; VOLOCHINOV, 2002).

Maria, no momento das entrevistas, sentia-se "realizada" e "equilibrada" por estar finalizando o Ensino Médio e estagiando. No entanto, a relação entre escola e estágio foi construída também tendo seu lado negativo, pois ela se cansa "muito", sente-se "estressada" e "preocupada" com as "duas coisas" e se sente "sem tempo". Para ela, "a vida é assim cansativa", é uma "luta". Porém, é essa "luta" que a faz "crescer" e buscar "algo melhor". Segundo ela, se vivesse na "maresia" não iria conseguir "nada na vida" e nem iria ser "alguém na vida".

Ao se posicionar como uma pessoa "lutadora" e "batalhadora", estes novos significados relacionados as suas experiências no trabalhoescola indicam que à medida que Maria reflete sobre si-mesma e os outros, constrói sua agencialidade (BRUNER, 1986), direcionada por qualidades relacionadas ao ser mulher (CAIXETA, 2001; 2006).

Maria se posicionou em suas narrativas relacionando-se ao contexto histórico, político, cultural, social e interpessoal, na medida em que compartilha os sistemas simbólicos presentes no seu contexto sociocultural (CORSON, 2000). Nesse sentido, entendemos que o processo de desenvolvimento acontece nas relações dialéticas interpessoais e intrapessoais, nas tensões entre os significados sociais compartilhados e os significados produzidos sobre si-mesma, 
em uma dada temporalidade, como podemos observar no seguinte trecho:

\begin{abstract}
O colégio me definiu muito o que eu tou sendo hoje. Eu tou sendo uma pessoa que eu tou vendo...tou sendo muito realista em tudo o que eu faço, não sou mais fantasiosa como eu era antes, né, na 6ạ série, aqui eu criei uma noção bem maior da vida, não tou sendo mais uma criançola, e a escola me mostrou, cara, tudo o que eu tenho que ser, né, e eu tou sendo uma pessoa que tou estudando, tou querendo ser alguém na vida, a escola definiu pra mim o que eu tinha que ser.
\end{abstract}

Para Maria, a relação entre trabalho-escola a possibilitou ser "mais realista", ao invés de ser "fantasiosa", como era no Ensino Fundamental. As atividades desenvolvidas no espaço de trabalho criaram as condições para que ela, sendo mãe solteira, sentisse e conquistasse a "liberdade", "independência" e "autonomia", por um lado, e, por outro lado, re-significasse o discurso ideológico e se posicionasse como uma "profissional competente e estudiosa".

Nas narrativas, os novos posicionamentos e significados sobre simesmo se constroem na tensão e na negociação entre os aspectos ideológicos (estudo como garantia de trabalho e sucesso com o "emprego bom" ao invés de um "emprego ruim"), os aspectos relacionados ao desenvolvimento pessoal no momento da entrevista ("liberdade", "independência", "autonomia" e ser uma "pessoa boa"). Na tensão e na negociação, Maria reconstrói as vozes como parte do si-mesmo, produzindo seus sistemas de significados e seus posicionamentos em relação a ser estudante e ser trabalhadora (HERMANS, 2001; HERMANS; KEMPEN; VAN LOON, 1992).

O processo de constituição de si-mesmo pode ser entendido como um produto da tensão entre as diferentes posições em um cronotopo, que no caso está definido por relações específicas entre escola e mundo do trabalho, onde essas posições se encontram em processo de negociação (MATUSOV; SMITH; CANDELA; LILU, 2007), cooperação, oposição, conflito, acordo e desacordo. Nessa relação, as posições individuais são construídas ao longo da vida da pessoa e são representadas pelos valores, pelas crenças, pelos objetivos e metas pessoais marcados pelos impactos emocionais e ideológicos dos eventos vivenciados (BAKHTIN, 1981). E as posições coletivas são construídas historicamente nos contextos socioculturais nos quais a pessoa atua.

$\mathrm{Na}$ construção de vários possíveis si-mesmos, no caso da participante, a transição para a vida adulta foi marcada ainda por escolhas ativas entre demandas contraditórias geradas pelo ser mãe na relação trabalho-escola, enfocada neste estudo. Maria relatou que na sua relação com a escola e o trabalho sente-se "cansada", "tendo 
que cumprir os horários da escola e do estágio para conseguir se manter no colégio e no estágio"; sente-se "estressada", "tendo que conciliar serviço, escola, filha, casa". Sente-se ainda "sacrificada", "leva bronca", "faz mais que a hora", "é julgada como nada", "ganha 390 reais sem direito a nada"; sente-se com "muita responsabilidade", "entrar em contato com outras pessoas", "mexer com o sistema bancário". Sente-se "sem tempo", pois a vida é "corrida": ela "tem horário para acordar, para sair de casa, para chegar ao serviço, para sair do serviço, para ir a casa, para ir à escola, para sair da escola, para voltar para casa".

Nesses trechos da fala de Maria, notamos que ela utiliza termos como "cansada", "estressada", "sacrificada", "responsabilidade", "levar tapa na cara", para compartilhar seus significados como também para se posicionar, indicando a orientação em direção à vida adulta. Sua narrativa é construída a partir de um ativo processo de posicionamento, onde a identidade pessoal é resultante dos diversos relacionamentos que a exigem. Ou seja, os diferentes posicionamentos foram representados dependendo do contexto relacional, tendo que reproduzir narrativas de estabilidade ou de mudança (DAVIES; HARRÉ, 1990).

Portanto, observamos que a narrativa de Maria se estrutura conforme as mudanças espaço-temporais que, nos resultados se concretizam na relação passado-presente-futuro e nos espaços da escola e do trabalho. Acrescentando-se que, no caso de Maria, a mudança nos posicionamentos escola-tabalho é construída, ao longo das cinco sessões, pela inversão do valor do "topo" escola-trabalho para trabalho-escola.

A utilização do caso de Maria, com relação às especificidades identificadas nas narrativas relacionadas ao impacto da gravidez na adolescência e ao uso de marcadores temporais na construção de seus posicionamentos na atividade de interpretação das relações trabalho-escola, possibilitou compreendermos as mudanças na adultez em emergência. O estudo de caso nos possibilitou a aplicação de procedimentos para a interpretação dos posicionamentos nas narrativas, como relatado detalhadamente a seguir.

\section{Emprego bom}

Ao observarmos o mapa dos significados, em relação ao tema "emprego bom", percebemos a inter-relação entre o trabalho e a escola na sua vida. Observarmos esta relação na seguinte fala de Maria sobre não-trabalho e trabalho:

quando você só estuda você vive no mundo assim, como fala, você vive no mundo muito criancinha, sei lá, quando você trabalha e estuda sua cabeça é outra, você cresce muito mais quando você estuda e trabalha você... você vê o que 
que é trabalhar, você vê o que que é um dinheiro, você sabe o que que é trampar [trabalhar] e, é um desenvolvimento muito grande que você tem.

Podemos observar na citação acima que os significados mediadores e reguladores dos posicionamentos foram tecidos na relação entre trabalho-escola, na tensão entre o passado (estudante $=$ criancinha), presente (estuda e trabalha $=$ crescimento noção de dinheiro e de trabalho) e futuro (desenvolvimento). É nesta tensão entre os significados que emerge a produção de novos significados na narrativa.

Observa-se na citação ainda uma transformação na produção de significado na relação entre trabalho-escola. Segundo Maria, "quando você só estuda, você vive no mundo assim... no mundo criancinha... quando você trabalha e estuda... você cresce muito mais... vê o que é trabalho, dinheiro...". A sua relação entre trabalho-escola está possibilitando uma mobilização e um direcionamento em sua transição para a vida adulta e uma re-significação e atualização dos seus significados e posicionamentos.

Observando ainda que a temporalidade nas narrativas da participante foi organizada a partir de marcas temporais em que o passado "antes" organiza-se nas narrativas como "estudante e criança", relacionado a uma época de ingenuidade e imaturidade. O presente "depois" organiza-se em suas narrativas como "estudante e trabalhadora", relacionado a uma época de crescimento, autonomia. E o futuro "depois", organiza-se como "desenvolvimento", relacionado à inserção na vida adulta. Considerando ainda essas marcas temporais, percebemos a entrada no mundo do trabalho como sendo um marco de mudança na vida da participante, indicando a emergência de novos significados ("conhece o significado de dinheiro e de trabalho e valoriza a escola").

Seu discurso concretiza o caráter ideológico dos significados sociais expressos pelos interesses e motivações pessoais, construindo uma direcionalidade para o futuro (BRUNER, 1997). Na fala de Maria, a relação entre trabalho-escola, desencadeada pelos eventos vivenciados em sua adolescência, está impulsionando a transição para a vida adulta pela tensão entre os aspectos ideológicos disponíveis nos discursos coletivos, permitindo que ela reflita, faça suas escolhas e tome decisões ("Eu tenho que enfiar na minha cabeça que eu tenho que estudar, eu tenho que me colocar nessa posição, eu não quero tipo, você ter... eu ser uma pessoa que venha trazer dinheiro para casa") e os aspectos emocionais, tais como: sentimento de crescimento pessoal, profissional e financeiro ("Pra você chegar em algum lugar, você tem que estudar e ser uma pessoa 
competente, você ser uma pessoa profissional, ser uma pessoa muito boa assim profissionalmente assim").

O direcionamento no processo de desenvolvimento de Maria é indicado também pela tensão entre a "criançola", no passado, a relação entre "estudo" e "trabalho", no presente, e a "competência profissional e pessoal", no futuro. No entanto, é mais marcante em sua fala a relação entre o agora e as perspectivas de futuro (“...ser uma pessoa muito boa assim profissionalmente assim").

$\mathrm{Na}$ tensão entre os aspectos coletivos e pessoais, Maria reconstrói as vozes coletivas e individuais como parte de si-mesma, produzindo seus sistemas de posicionamentos e significados em relação a ser estudante e ser trabalhadora (HERMANS, 2001; HERMANS; KEMPEN; VAN LOON, 1992). Os aspectos ideológicos das informações empíricas indicam que na construção do "emprego bom", há a tensão e a negociação entre o discurso como garantia de trabalho e sucesso em um emprego bom, em oposição a um emprego ruim: "Se você não estuda, você já era, você não é nada, você não é nem um varredor...Pra você chegar em algum lugar, você tem que estudar e ser uma pessoa competente..." e os aspectos relacionados ao desenvolvimento pessoal no momento da entrevista: liberdade, independência, autonomia e ser uma pessoa boa ("...você adquire mais conhecimento, você se conhece mais como pessoa, você quer voar, você não tem limites, você quer seguir em frente").

\section{I ndependência}

Como resultante da tensão entre os significados e interpretação acerca do "trabalho bom" e "trabalho ruim", "estudo" e "não-estudo", os significados e necessidades são atualizados como percebemos no tema "independência", que expressa uma série de valores pessoais e coletivos. Para Maria, o termo independência é mediado e regulado pelas relações entre os seguintes significados: "dinheiro", "autonomia", "liberdade", "mostrar quem é", "conquista" e "pessoa não inútil". Em oposição ao termo "dependência" há: "sem autonomia", "inútil", "sem responsabilidade". Tais significados estão mediando a produção do sentindo de realização. Este significado é característico da vida adulta, onde as transformações históricas e socioculturais das relações econômicas vêm produzindo idéias, crenças, valores e conceitos de que a vida adulta é marcada pela entrada no mundo do trabalho. Este, ao longo do tempo, produz conceitos em que o trabalhador precisa ser competente (LEITE, 1995; PASTORE, 1995; RACHID; GITAHY, 1995). Como podemos observar na seguinte fala:

é... um passo para você ter liberdade na vida, porque assim que você termina o colégio, você corre atrás de vestibular, passa, passa na faculdade, né, continua estudando e 
consegue um trampo e a primeira coisa que você quer é sair de casa. Então, você quando você chega no ensino médio você já começa a criar assim, você começa a querer voar, então, é uma coisa assim pra mim, que é uma descoberta muito louca da vida.

Neste trecho, a temporalidade construída pela justaposição de eventos corrobora com os estudos sobre o assunto (ABRAMO; VENTURINI, 2000; LIRA; MEDRADO; NASCIMENTO; GALINDO; MORAES; PEDROSA, 2002; SHANAHAN, 2000) que indicam que os jovens contemporâneos marcam os significados da vida adulta a partir dos mesmos eventos, no entanto, postergando os mesmos para o futuro, que no caso de Maria foi possivelmente antecipado pela gravidez na adolescência.

No trecho acima, notamos que os significados mediadores e reguladores do tema independência estão sendo produzidos em tensão com os significados de dependência e a ambivalência entre os dois temas direciona o processo de desenvolvimento de Maria para a vida adulta, na medida em que produz significados como "saída da casa dos pais", "independência", "autonomia" e "realização" em oposição ao termo "querer voar".

\section{Vida Dura}

Em relação ao tema vida dura, podemos observar nas enunciações de Maria a construção de sentimentos que mediam os seus posicionamentos sobre ser jovem e não ser jovem, ser adulta e não ser adulta e à medida que os construía notamos a tensão que desencadeava o seu direcionamento para o futuro. O período da juventude como a fase das primeiras experiências profissionais e, portanto, com a vivência das primeiras dificuldades no processo de conquista do primeiro emprego, por isso, o contexto do mundo do trabalho é relevante para a análise do futuro dos jovens, em particular, o lugar que o trabalho e a profissão ocupam no âmbito de suas preocupações e aspirações (CARVALHO, 2005).

O mundo do trabalho traz em sua história a idéia de que o crescimento profissional, pessoal e financeiro é um produto da relação entre trabalho-escola. Nesse discurso se transmite ainda que o profissional com muito esforço, persistência, trabalho e estudo, conquista o sucesso e a felicidade profissional e pessoal e financeira (CHAUí, 2006). Os posicionamentos e direcionamentos de Maria a possibilitaram vivenciar caminhos sociais diferentes que, por sua vez, desencadearam a sua reflexão sobre suas experiências e a resignificação cognitiva, emocional e moral, utilizando-as para explicarse e posicionar-se (WANG; BROCKMEIER, 2002).

Maria diz-se "feliz" e "realizada", pois está conseguindo ter "esse sucesso transmitido pela sociedade e pela cultura". Relatou que "estagia em um lugar gratificante que representa os vários anos de 
estudo"; sente-se "realizada" na profissão e nos estudos; sente-se "satisfeita" por "conseguir ter sucesso"; sente-se "madura" e "não jovem", "me viro sozinha e já passei por muitas coisas que tiraram minha juventude, como a gravidez, o abandono do esporte, o casamento, a separação, a ida à Salvador para morar com meu pai, o retorno a Brasília para morar com minha mãe, as experiências da escola e no trabalho".

Para ela, "jovem é um período muito tumultuado, muito estressante, de muita curiosidade, de fazer coisas loucas, de ouvir "reggae", "rock and roll", fazer "muita bagunça". Na descoberta da maturidade "você convive com pessoas diferentes, não fica mais na lengalenga de mamãe e papai, se encontra profissionalmente, define o caráter, você pode ir para o lado bom (subir) ou para o lado ruim (descer)".

As transformações nos posicionamentos garantem a distância das situações presentes, na medida em que cada posição cria uma voz que se relaciona com outras vozes em uma dinâmica dialógica, possibilitando a construção de significados de si-mesma em relação aos outros (DAVIES; HARRÉ, 1990; HERMANS; HERMANS-J ANSEN, 2003; HERMANS, 2001; HERMANS, 1996; JOSEPHS; VALSINER; SURGAN, 1999; VALSINER, 2007; VALSINER, 2004; VALSINER; CONNOLLY, 2003).

A relação entre o que é vivenciado na escola e no trabalho e o que é construído por Maria a partir de suas experiências estabelecem a estrutura para os modos em que se constitui, se identifica, se posiciona, transformando os diferentes espaços, conforme as mudanças temporais.

\section{Conclusão}

Este estudo, conforme explicitado anteriormente, faz parte de uma pesquisa mais ampla que teve como objetivo investigar a construção de significados e os posicionamentos sobre ser jovem, estudante e trabalhador. Neste artigo, enfocamos a narrativa de uma aluna do Ensino Médio da Educação de Jovens e Adultos, de uma escola pública do Distrito Federal que trabalha em um banco público do Distrito Federal, pois em suas narrativas são evidenciados o momento de impacto do evento de gravidez na adolescência e marcadores temporais que são relevantes no direcionamento da produção de posicionamentos e de significados na relação trabalho-escola.

Observamos na fala de Maria, que a sua transição para a vida adulta foi desencadeada pelos eventos de gravidez e maternidade aos 15 anos e foi marcada pela construção de significados de três temas centrais, que se caracterizam a partir dos significados opostos: o estudo e o não estudo, o trabalho formal e o trabalho informal, à medida que a participante se posicionava no presente em relação ao passado e se projetava para o futuro, se constituindo como estudante e trabalhadora. 
Esse processo é resultante da tensão do diálogo na relação dialética de Maria (seus desejos, objetivos, crenças e valores) com as outras pessoas nos espaços da escola e do trabalho, à medida que há o constante processo de negociação. A relação trabalho-escola possibilitou a inclusão da jovem na sociedade e no mundo de trabalho, mediando a construção dos sentimentos vivenciados nos dois contextos em relação à sua vida.

Notamos que a sua transição para a vida adulta está se constituindo pelo impacto da maternidade como um momento do curso de vida construído na relação Eu - Outro em que há ênfase nos seguintes posicionamentos: eu - adulto, eu - estudante, eu - responsável, eu independente, eu - trabalhador; e a necessidade de negociação com as antigas posições, relativas ao início da adolescência, como eu estudante, eu - jovem, eu - curtição, eu - rebelde, eu - dependente, além do constante diálogo com outras pessoas na escola e no trabalho, como os professores, a direção, os chefes e os amigos.

Concluímos que Maria na sua narrativa foi se posicionando como uma pessoa "autônoma", "alguém na vida", "uma profissional", "feliz", "realizada", "realista", "responsável", "madura" ao mesmo tempo em que construía os significados mediadores do contexto escolar, como "estudar" e ser "competente" e do contexto do trabalho, como "dinheiro", "autonomia", "respeito", "inclusão" e "crescimento pessoal, profissional e independência".

Nas narrativas de Maria, os significados construídos pelo impacto gerado pelos eventos da gravidez e de maternidade na adolescência na relação entre trabalho-escola direcionou 0 vetor de desenvolvimento para a vida adulta: “...tenho que estudar, eu tenho que me colocar nesta posição, eu não quero tipo... eu quero ser uma pessoa que venha trazer dinheiro para casa...", marcados pela tensão entre "se virar sozinha", "ter responsabilidade" relacionados à adultez e o ser jovem, como um "período tumultuado", "estressante", "de irresponsabilidade" e "muita curiosidade".

\section{Referências Bibliográficas}

ABBEY, E.; VALSINER, J. Emergence of meanings through ambivalences. Forum: qualitative social research, Berlin, v. $6, \mathrm{n}$. 1, s/p, 2005.

ABRAMO, H.; VENTURINI, G. Juventude, política e cultura. Sociedade: Juventude, política e cultura, São Paulo: Fundação Perseu, 2000.

BALL, A. F. Teachers' developing philosophies on literacy and their use in urban schools: a vigotskian perspective on internal activity and teacher change. In: LEE, C. D.; SMAGORINSKY, P. (Orgs.). Vigotskian perspectives on literacy research: constructing meaning through collaborative inquiry. Cambridge: Cambridge University Press, p. 226-255, 2005. 
BAKHTIN, M. M. The dialogic imagination: four essays. Austin: University of Texas Press, 1981.

BAKHTIN, M. M. Estética da criação verbal. São Paulo: Cultrix, 1992.

BAKHTIN, M. M. Toward a philosophy of the act. In: LIAPUNOV, V; HOLQUIST, M. (Eds.). Toward a philosophy of the act. Austin: University of Texas, 1993.

BAUER, M. W.; GASKELL, G. Pesquisa qualitativa com texto, imagem e som - um manual prático. Petrópolis: Vozes, 2004.

BARBATO, S. B.; CAIXETA, J. E. História de vidas, identidade e memória: uma proposta metodológica. In: CABRAL, L; MOITA LOPES, L. P. (Orgs.). Estudos de identidade: entre saberes e práticas 01. Rio de Janeiro: Garamond/FAPERJ, v. 1, p. 01-12, aceite.

BERK, L. Child development. Illinois State University: Pearson, 2006.

BRANCO, A. M. C. U. A.; ROCHA, R. F. A questão da metodologia na investigação científica do desenvolvimento humano. Psicologia: Teoria e Pesquisa, Brasília v. 14, n. 3, p. 251-258, 1998.

BRASI L. Diretrizes Curriculares Nacionais: Educação Básica: Conselho Nacional de Educação: Brasília, 2001.

BROCKMEIER, J. Reaching for meaning: human agency and the narrative imagination. Theory \& Psychology, Thousand Oaks, CA, v. 19, n. 2, p. 213-233, 2009.

BRUNER, J. Atos de significação. Porto Alegre: Artes Médicas, 1997.

BRUNER, J. Actual minds, possible worlds. Cambridge, MA: Harvard, University Press, 1986.

BRUNER, J. From communication to language: a psychological perspective. Cognition, Amsterdam, v. 3, n. 195, p. 255-287, 1975.

BRUNER, J; FELDMAN, C. F. Group narrative as a culture context of autobiography. In: RUBIN, D. (Org.). Remembering our past: studies in autobiographical memory. Cambridge: Cambridge University Press, 1996, p. 291-317.

CAIXETA, J. E. Guardiãs da memória: tecendo significações sobre si, suas fotografias e seus objetos. 2006. Tese (Doutorado em Psicologia) - Universidade de Brasília.

A mulher em envelhecimento no seu cotidiano: diálogos, textos e imagens sobre a identidade feminina. 2001. Dissertação (Mestrado em Psicologia) - Universidade de Brasília.

CARLUCCI, A. P. A relação trabalho-escola na narrativa de jovens: um estudo sobre significados e posicionamentos na transição para a vida adulta. 179f. 2008. Dissertação (Mestrado em Processo de Desenvolvimento Humano e Saúde) - Instituto de Psicologia da Universidade de Brasília, Brasília. 
CARVALHO, O. F. A formação profissional no século XXI: fundamentos e perspectivas. Educação, Trabalho e Sociedade, vol. 2, Brasília: SESI, 2005.

CORREIA, G. F. A escola promete, a criminalidade dá: o dilema vivido por jovens marginalizados, Dissertação de Mestrado em Psicologia, Universidade de Brasília, Conselho Nacional de Desenvolvimento Científico e Tecnológico, 2001.

CORSON, D. Vocabulario y memória coletiva. In: ROSA, A. Memória coletiva e identidade nacional. Biblioteca Nueva, Universidade Autonoma de Madrid, 2000.

CHAUÍ, M. O que é ideologia. São Paulo: Brasiliense, 2006.

CRESWELL, J. W. Qualitative inquiry and research design: choosing among Five traditions. Thousand Oaks, California: Sage Publications, 1998.

DAVIES, B; HARRÉ, R. Positioning: the discursive prodution of selves, London: Sage Publication, 2001.

DORNAS, R. G. P. Diretrizes e bases da educação nacional: comentários e anotações. Belo Horizonte: Modelo Editorial, 1997.

FRIGOTTO, G. (Org.). Educação e crise do trabalho: perspectivas de final de século. Petrópolis, RJ: Vozes, 1998.

GERGEN, K. Self-Narration in social life. In: WETHERELL, M.; TAYLOR, S.; YATES, S. J. Discourse theory and practice: a reader. London - Thousand Oaks - New Delhi: Sage Publication, 2001, p. 247-260. GRAMISC, A. Concepção dialética da história. Rio de Janeiro: Civilização Brasileira, 1966.

HALLBWACHS, M. A memória coletiva. São Paulo: Centauro, 2006. HERMANS, H. J. M. Voicing the self: form information processing to dialogical interchange. Psychological Bulletin, Washington, DC, v. 119, n. 1, p. 31-50, 1996.

HERMANS, H. J. M. The dialogical self: toward a theory of personal and culture positioning. Culture \& Psychology, Worcester, MA, v. 7, n. 3, p. 243-281, 2001.

HERMANS, H. J. M; HERMANS-JANSEN, E. Dialogical processes and development of the self. In: VALSINER, J.; CONNOLLY, K. J. Handbook of developmental psychology. London - Thousand Oaks - New Delhi: SAGE Publications, p. 534-559, 2003.

HERMANS, H. J. M.; KEMPEN, H.; VAN LOON, R. J. P. The dialogical self: beyond individualism and rationalism. American Psychologist, Washington, DC, v. 47, n. 1, p. 23-33, 1992.

JENSEN, A. J. Emerging adulthood: a theory of development from the late teens through the twenties. American Psychological Association, Washington, DC, v. 55, n. 5, p. 469-480, 2000.

JOSEPHS, I. E. The Hopi in me: the construction of a voice in the dialogical self from a cultural psychology perspective. Theory \& Psychology, Thousand Oaks, CA, v. 12, n. 2, p. 161-173, 2002. 
JOSEPHS, I. E.; VALSINER, J.; SURGAN, S. E. The process of meaning construction: dissecting the flow of semiotic activity. In: BRANDTSTÄDLTER, J .; LERNER, R. M. Action \& self-development: theory and research through the life span. Califórnia: Thousam OASCA, 1999.

LAWRENCE, J. A.; DODDS, A. E. Myself, the project: sociocultural interpretations of young adulthood. In: VALSINER, J.; ROSA, A. (Orgs.). The Cambridge Handbook of sociocultural psychology. Cambridge: Cambridge University Press, 2007, p. 404-422.

LEITE, E. M. Educação, trabalho e desenvolvimento: o resgate da qualificação. Em aberto: educação, trabalho e desenvolvimento, Brasília, n. 65, v. 15, p. 9-20, 1995.

LINELL, P. Troubles with mutualities: towards a dialogical theory of misunderstanding and miscommunication. In: MARKOVÁ, I.; GRAUMAN, C. F.; FOPPA, K. (Eds.). Mutualities in dialogical. Cambridge: Cambridge University Press, 1995, p. 176-213.

LYRA, J.; MEDRADO, B.; NASCIMENTO, P.; GALINDO, D.; MORAES, M.; PEDROSA, C. A gente não pode fazer nada, só podemos decidir sabor de sorvete. Adolescentes: de sujeito de necessidades a um sujeito de direitos. Cadernos Cedes, Campinas, v. 22, n. 57, p. 1-7, 2002.

MANFREDI, S. M. Educação profissional no Brasil. São Paulo: Cortez, 2003.

MATUSOV, E.; SMITH, M.; CANDELA, M. A.; LILU, K. "Culture has no internal territory": culture as dialogue. In: VALSINER, J.; ROSA, A. (Orgs.). The Cambridge Handbook of sociocultural psychology. Cambridge: Cambridge University Press, 2007, p. 460-483.

MELO, G. S. Diálogos com profissionais de Ensino Especial: o contexto histórico-cultural e suas repercussões na prática educacional do Distrito Federal, Dissertação em Processos de Desenvolvimento Humano e Saúde, Instituto de Psicologia, da Universidade de Brasília, Brasília, 2003.

MEY, G. Qualitative research and the analysis of processes: considerations towards a "qualitative developmental psychology". Forum: qualitative social research, v. 1, n. 1, p. 1-18, 2000. Disponível em: qualitative-research, <http://www.qualitativeresearch.net/fqs-texte/1-00/1-00mey-e_p.html>. Acesso em: 21 abr. 2005.

PASTORE, J. O futuro do trabalho no Brasil e no Mundo. Em aberto: educação, trabalho e desenvolvimento, Brasília, n. 65, v. 15, p. 31-38, 1995.

RACHID, A.; GITAHY, L. Programas de qualidade, trabalho e educação. Em aberto: educação, trabalho e desenvolvimento, Brasília, n. 65, v. 15, p. 58-65, 1995.

ROMMETVEIT, R. On the architecture of intersubjectivity. In: ROMMETVEIT, R.; BLAKAR, R (Eds.). Studies of language, thought 
and verbal communication. London: Academic Press, 1979, p. 93108.

SANTOS, P. F.; BARBATO, S. B. Concepções de professores sobre a inclusão escolar de alunos com distúrbios neuromotores. Linhas Críticas, Brasília, v. 12, n. 23, p. 245-260, 2006.

SHANAHAN, $M$. Pathways to adulthood in changing societies: variability and mechanisms in life course perspective. Annual Review of Sociology, Palo Alto, CA, v. 26, p. 667-692, 2000.

VALSINER, J. The promoter sign: developmental transformation within the structure of dialogical self. Trabalho apresentado no Simpósio de Developmental aspects of the dialogical self ( Hubert Hermans, Convener). ISSB, Gent, Bélgica, 2004.

Culture in minds and societies: foundations of cultural psychology. Los Angeles, London, New Delhi, Singapore: Sage Publications, 2007.

VALSINER, J.; CONNOLLY, K. J. (Orgs.). The nature of development: the continuing dialogue of processes and outcomes. In:

Handbook of developmental psychology. London - Thousand Oaks - New Delhi: SAGE Publications, 2003, p. 09-18.

VALSINER, J.; ROSA, A. Cambridge Handbook of sociocultural psychology. New York: Cambridge University Press, 2007.

VIGOTSKI, L. S. A formação social da mente. São Paulo: Martins Fontes, 1998.

VIGOTSKI, L. S. A construção do pensamento e da linguagem. São Paulo: Martins Fontes, 2001.

VOLOCHINOV, V. N. Marxismo e filosofia da linguagem: problemas fundamentais do método sociológico na ciência da linguagem. São Paulo: Editora HUCITEC ANNABLUME, 2002.

WANG, Q; BROCKMEIER, J. Autobiographical remembering as cultural practice: understanding the interplay between memory, self, and culture. Culture \& Psychology, Worcester, MA, v. 8, n. 1, p. 54-64, 2002.

WINEGAR, L. T. Developmental research and comparative perspectives: applications to developmental science. In: TUDGE, J.; SHANAHAN, M. J.; VALSINER, J. (Orgs.). Comparisons in human development: understanding time and context. New York: Cambridge University Press, 1997, p. 13-33.

\section{Endereço para correspondência}

Ana Paula Carlucci

Universidade de Brasília, Instituto de Psicologia, Departamento de Psicologia Escolar e do Desenvolvimento, Labmis. ICC Sul - Campus Darcy Ribeiro. Asa Norte, CEP 70910-900 - Brasília, DF - Brasil.

Endereço Eletrônico: apcarlucci@gmail.com

Silviane Barbato 
Universidade de Brasília, Instituto de Psicologia, Departamento de Psicologia Escolar e do Desenvolvimento. ICC Sul - Campus Darcy Ribeiro. Asa Norte, CEP 70910-900 - Brasília, DF - Brasil.

Endereço Eletrônico: barbato.silviane@gmail.com

Olgamir Carvalho

Universidade de Brasília, Faculdade de Educação, Departamento de Teoria e Fundamentos. - Campus Darcy Ribeiro. Asa Norte, CEP 70910-900 - Brasília, DF Brasil.

Endereço Eletrônico: olgamir@unb.br

Recebido em: 06/11/2009

Reformulado em: 31/08/2010

Aceito para publicação em: 27/09/2010

Acompanhamento do processo editorial: Rita Maria Manso de Barros

\section{Notas}

* Doutoranda do Programa de Pós-Graduação em Processos de Desenvolvimento Humano e Saúde, do Instituto de Psicologia, pela Universidade de Brasília, como bolsista CAPES. Mestre no Programa de Pós-Graduação em Processos de Desenvolvimento Humano e Saúde, do Laboratório de Microgênese das Interações Sociais, do Departamento de Psicologia Escolar e do Desenvolvimento, do Instituto de Psicologia da Universidade de Brasília (UnB), como bolsista CNPq. Formada em Psicologia pela Universidade Católica de Brasília (UCB). Área de concentração em Desenvolvimento Humano e Educação. Atualmente participa da linha de Pesquisa Processos de Desenvolvimento e Cultura, Projeto de Pesquisa Identidade, memória e narrativa.

**Pesquisadora CNPq do Laboratório de Microgênese nas Interações Sociais. Licenciada em Língua e Literatura pela Universidade de Brasília, Mestre em Lingüística Aplicada pela Universidade de Durham, Inglaterra, Doutora em Psicologia pela UnB (CNPq), com pós-doutorado pelos Depts. de Psicopedagogia de Universidade de Alcalá e de Psicologia Básica da Universidade Auntónoma de Madri, Espanha (CAPES). Atualmente, Professora Adjunta do Instituto de Psicologia da Universidade de Brasília - UnB, recebe auxílio pesquisa do CNPq, do FUNPE/DPP/UnB e FINATEC e AECID e Fundación Carolina, Espanha.

*** Coordenadora e pesquisadora do Núcleo de Estudos e Pesquisas em Educação e Trabalho - NEPET. Licenciada em Pedagogia pela Universidade de Brasília, Mestre em Educação pela Pontifícia Universidade Católica de São Paulo - PUC, Doutora em Educação pela Universidade Estadual de Campinas - UNICAMP Atualmente, Professora Adjunta da Faculdade de Educação da Universidade de Brasília - UnB, coordenadora da linha de pesquisa sobre políticas públicas e gestão da educação profissional e tecnológica, responsável pela formação em âmbito de mestrado dos gestores da rede federal de educação profissional e tecnológica do país, numa parceria com a SETEC/MEC.

${ }^{1}$ Este trabalho recebe fomento do CNPq, via bolsa n. 134091/2007-8, e o apoio de equipamento da Funpe/2006, DDP/UnB. Recebeu também apoio da FINATEC, FUNPE/UnB e da CAPES por meio de bolsa de Pós-Doutorado para a segunda autora e do fomento para o Projeto "Memória, Identidade e Cultura Cidadã" do Intercâmbio Internacional CAPES-DGU LABMIS/IP/UnB e Autónoma de Madrid, Espanha. 